Gut, 1967, 8, 325

\title{
Carbohydrate metabolism in duodenal ulcer patients
}

\author{
K. D. BUChANAN, M. T. McKIDDIE, A. C. LINDSAY, AND W. G. MANDERSON \\ From The Royal Infirmary, Glasgow
}

EDITORIAL COMMENT After oral glucose plasma insulin levels were higher in patients with duodenal ulcer than in normal controls. It is suggested that this might conceivably be a factor in the production of increased acid secretion.

Hypoglycaemia is a potent stimulus to gastric secretion via the vagus, and may be used as a test of vagal integrity (Hollander, 1946). The possibility that hypoglycaemia may predispose towards peptic ulceration has intrigued several workers (Muir, 1949; Berry, 1957; Etienne-Martin, Klepping, Petit, Guerrin, and Michiels, 1960). In contrast, patients with diabetes mellitus have a lowered incidence of peptic ulcer (Dotevall, 1959) and lower gastric secretion (Dotevall, 1961). This is possibly the result of the higher incidence of atrophic gastritis in diabetics (Arapakis, Bock, Williams, and Witts, 1963) which may be secondary to the formation of autoantibodies (Moore and Neilson, 1963). However, Caridis, Blair, Kilpatrick, and Carr (1966) have shown that alloxan inhibits the gastric acid output in rats, and they concluded that this reduction was possibly due to hyperglycaemia.

The present study is concerned with blood sugar and plasma insulin levels in patients with duodenal ulceration. As it is now recognized that the effects of oral glucose administration differ from those of intravenous glucose (McIntyre, Holdsworth, and Turner, 1964), the patients have been studied both after oral and intravenous administration of glucose.

\section{MATERIALS AND METHODS}

The patients studied were 14 young men, age range 15-38 years, who had been admitted to hospital because of persistent dyspeptic symptoms. All had radiological evidence of duodenal ulceration without delayed gastric emptying. None was more than $10 \%$ above ideal body weight but several were underweight. None had a family history of diabetes mellitus and all had been eating a diet containing adequate carbohydrate.

The control group consisted of 14 healthy male volunteers of age range $20-31$ years. All were within $10 \%$ of ideal body weight and none had a family history of diabetes mellitus.

Oral glucose tolerance tests were performed after an overnight fast, venous blood being removed for blood sugar estimation and plasma insulin assay, fasting, and $15,30,60,90,120$, and 150 minutes after $50 \mathrm{~g}$. of oral glucose.

Intravenous glucose tolerance tests were performed also after an overnight fast, $50 \mathrm{ml}$. of a $50 \%$ dextrose solution being injected over a four-minute period and venous blood removed for blood sugar and plasma insulin assay fasting and at $10,20,30,40,50$, and 60 minutes after the mid-point of the glucose injection (Lundbaek, 1962).

In the duodenal ulcer patients, augmented histamine tests (Kay, 1953) were also performed, the total volume of gastric juice and its free and total acid being estimated before and after injection of histamine. Plasma insulin was estimated by the immuno-assay technique of Hales and Randle (1963) and standards and antisera were as reported elsewhere (Buchanan and McKiddie, 1967a).

Blood sugar was estimated by an AutoAnalyzer using a modification of the Hagedorn-Jenson method.

\section{RESULTS}

ORAL GLUCOSE TOLERANCE TESTS Blood sugar results following oral glucose are shown in Table I. One duodenal ulcer patient (P.B.) had a lag curve; the remainder had normal glucose tolerance. Four of the patients and two controls showed levels below $60 \mathrm{mg}$. $/ 100 \mathrm{ml}$. after the initial rise but none had hypoglycaemic symptoms. The mean blood sugar values were higher in the duodenal ulcer patients than in the controls at 15,30 , and 60 minutes but this difference was only significant at 15 minutes $(P>0.05)$.

The peak blood sugar value, irrespective of timing, was higher in the ulcer patients than in the controls 
TABLE I

BLOOD SUGAR RESPONSE FOLLOWING $50 \mathrm{~g}$. ORAL GLUCOSE IN DUODENAL ULCER SUBJECTS AND CONTROLS

\begin{tabular}{|c|c|c|c|c|c|c|c|c|}
\hline \multirow[t]{2}{*}{ Subject } & \multirow[t]{2}{*}{ Age } & \multicolumn{7}{|c|}{ Blood Sugar Level (mg./100 ml.) } \\
\hline & & Fasting & 15 Minutes & 30 Minutes & 60 Minutes & 90 Minutes & 120 Minutes & 150 Minutes \\
\hline $\begin{array}{l}\text { Duodenal Ulcers } \\
\text { A.O. } \\
\text { C.W. } \\
\text { I.N. } \\
\text { R.B. } \\
\text { D.R. } \\
\text { J.J. } \\
\text { M.C. } \\
\text { R.A. } \\
\text { C.F. } \\
\text { A.H. } \\
\text { W.K. } \\
\text { A.C. } \\
\text { A.B. } \\
\text { P.B. }\end{array}$ & $\begin{array}{l}26 \\
31 \\
21 \\
20 \\
24 \\
15 \\
24 \\
29 \\
33 \\
38 \\
38 \\
32 \\
26 \\
30\end{array}$ & $\begin{array}{l}94 \\
93 \\
97 \\
96 \\
90 \\
90 \\
94 \\
90 \\
92 \\
75 \\
98 \\
90 \\
72 \\
87\end{array}$ & \begin{tabular}{r|}
132 \\
149 \\
111 \\
128 \\
108 \\
146 \\
120 \\
92 \\
134 \\
118 \\
137 \\
125 \\
134 \\
132
\end{tabular} & $\begin{array}{l}120 \\
164 \\
104 \\
164 \\
115 \\
137 \\
134 \\
114 \\
152 \\
128 \\
159 \\
155 \\
142 \\
188\end{array}$ & $\begin{array}{r}116 \\
150 \\
95 \\
158 \\
94 \\
107 \\
80 \\
94 \\
98 \\
118 \\
141 \\
80 \\
70 \\
148\end{array}$ & \begin{tabular}{|r|r|}
110 \\
88 \\
91 \\
116 \\
40 \\
103 \\
54 \\
98 \\
80 \\
78 \\
120 \\
43 \\
62 \\
103
\end{tabular} & $\begin{array}{l}80 \\
84 \\
90 \\
96 \\
56 \\
82 \\
81 \\
95 \\
81 \\
50 \\
92 \\
58 \\
80 \\
72\end{array}$ & $\begin{array}{l}62 \\
87 \\
83 \\
75 \\
74 \\
88 \\
90 \\
84 \\
56 \\
90 \\
74 \\
68 \\
72\end{array}$ \\
\hline Means \pm S.D. & $28 \pm 7$ & $90 \pm 8$ & $126 \pm 14$ & $141 \pm 24$ & $111 \pm 29$ & $85 \pm 26$ & $78 \pm 15$ & $77 \pm 11$ \\
\hline $\begin{array}{l}\text { Controls } \\
\text { I.A. } \\
\text { A.M. } \\
\text { T.G. } \\
\text { A.C. } \\
\text { R.H. } \\
\text { K.B. } \\
\text { G.M. } \\
\text { W.P. } \\
\text { K.C. } \\
\text { I.C. } \\
\text { J.McD. } \\
\text { A.W. } \\
\text { V.D. } \\
\text { S.A. }\end{array}$ & $\begin{array}{l}25 \\
26 \\
25 \\
31 \\
24 \\
30 \\
24 \\
24 \\
24 \\
21 \\
23 \\
20 \\
25 \\
24\end{array}$ & $\begin{array}{r}94 \\
90 \\
106 \\
76 \\
92 \\
97 \\
92 \\
97 \\
102 \\
101 \\
82 \\
93 \\
98 \\
95\end{array}$ & $\begin{array}{l}118 \\
105 \\
120 \\
1 \overline{110} \\
114 \\
112 \\
\frac{120}{120} \\
\frac{118}{100} \\
108 \\
133\end{array}$ & \begin{tabular}{r|}
138 \\
115 \\
150 \\
108 \\
100 \\
152 \\
113 \\
160 \\
149 \\
96 \\
117 \\
120 \\
126 \\
152
\end{tabular} & $\begin{array}{r}136 \\
78 \\
152 \\
81 \\
100 \\
97 \\
72 \\
106 \\
62 \\
80 \\
95 \\
100 \\
111 \\
107\end{array}$ & $\begin{array}{r}118 \\
80 \\
92 \\
75 \\
80 \\
67 \\
73 \\
75 \\
70 \\
75 \\
50 \\
97 \\
115 \\
104\end{array}$ & $\begin{array}{r}102 \\
81 \\
70 \\
81 \\
59 \\
72 \\
85 \\
56 \\
74 \\
89 \\
55 \\
90 \\
106 \\
100\end{array}$ & $\begin{array}{c}82 \\
86 \\
\overline{81} \\
\overline{-} \\
\overline{102} \\
\overline{85} \\
\overline{-} \\
\overline{92} \\
70\end{array}$ \\
\hline $\begin{array}{l}\text { Means } \pm \text { S.D. } \\
\text { Significance (P) }\end{array}$ & $\begin{array}{l}25 \pm 3 \\
0 \cdot 20\end{array}$ & $\begin{array}{l}94 \pm 8 \\
0.20\end{array}$ & $\begin{array}{l}114 \pm 9 \\
0.05\end{array}$ & $\begin{array}{l}128 \pm 21 \\
0 \cdot 20\end{array}$ & $\begin{array}{l}98 \pm 24 \\
0 \cdot 20\end{array}$ & $\begin{array}{l}84 \pm 19 \\
0.90\end{array}$ & $\begin{array}{l}80 \pm 17 \\
0.90\end{array}$ & $\begin{array}{l}85 \pm 10 \\
0 \cdot 10\end{array}$ \\
\hline
\end{tabular}

but not significantly so $(143 \pm 22: 131 \pm 19, \mathrm{P}=$ $0 \cdot 20$ ).

The plasma insulin values showed a wide variation both in patients and controls (Table II). The mean values (calculated on a log normal distribution) were higher in the duodenal ulcer patients than in the controls, the differences attaining significance at 30 and 60 minutes after glucose $(P>0.05$ and $\mathbf{P}>0.01$ respectively). All but one of the duodenal ulcer patients (A.H.) had the peak insulin level within 30 minutes whereas six of the control subjects had the peak insulin level after 30 minutes. The peak insulin level, irrespective of timing was significantly higher in the ulcer patients than in the controls $(148+50: 100+41 ; P>0.05)$.

INTRAVENOUS GLUCOSE TOLERANCE TESTS All subjects showed a normal rate constant ( $K$ value) for glucose disappearance except one of the duodenal ulcer patients (A.B.) who had a borderline value, $K=1 \cdot 0$. (The explanation for this is uncertain. He had normal oral glucose tolerance and plasma insulin levels following intravenous glucose resembled the mean values.)
The mean blood sugar values (Table III) for the two groups were not significantly different. The individual $K$ values are shown in Table IV. The mean value in the controls (2.9) is slightly higher than in the ulcer patients $(2 \cdot 2)$ but this is almost completely explained by one subject (I.C.) who had a $\mathrm{K}$ value of 11.6 .

The plasma insulin levels again showed a wide range (Table IV). The mean values are almost identical. All but two of the ulcer patients had the peak value at 10 minutes whereas five of the controls had a later peak value. The mean peak level, irrespective of timing, was slightly lower in the duodenal ulcer patients than in the controls but not significantly so $\left(78 \underset{-33}{+57}: 87_{-36}^{+61} ; P=0.60\right)$.

COMPARISON OF INSULIN RESPONSE TO ORAL AND INTRAVENOUS GLUCOSE The insulin responses to oral and intravenous glucose were not directly comparable as the dose and duration of the stimulus were different. However, it seemed valid to compare the duodenal ulcer patients with control subjects in respect to the relative insulin response to oral and intravenous glucose. 
TABLE II

PLASMA INSULIN RESPONSE TO $50 \mathrm{~g}$. ORAL GLUCOSE IN DUODENAL ULCER SUBJECTS AND CONTROLS

Plasma Insulin Level ( $\mu$-units/ml.)

\begin{tabular}{|c|c|c|c|c|c|c|c|}
\hline & Fasting & 15 Minutes & 30 Minutes & 60 Minutes & 90 Minutes & 120 Minutes & 150 Minutes \\
\hline \multicolumn{8}{|l|}{ Duodenal Ulcer } \\
\hline A.O. & 21 & 120 & 71 & 一 & 28 & 16 & 10 \\
\hline C.W. & 52 & 225 & 318 & 275 & 61 & 46 & 47 \\
\hline I.N. & 27 & 174 & 222 & 109 & 61 & 35 & 23 \\
\hline R.B. & 29 & 87 & 132 & 68 & 88 & 51 & 49 \\
\hline D.R. & 24 & 78 & 154 & 98 & 36 & 28 & - \\
\hline J.J. & 27 & 183 & 218 & 183 & 168 & 55 & - \\
\hline M.C. & 28 & 98 & 195 & 75 & 30 & 25 & 36 \\
\hline R.A. & 23 & 31 & 74 & 67 & 64 & 64 & 36 \\
\hline C.F. & 17 & 65 & 83 & 55 & 31 & 17 & 13 \\
\hline A.H. & 20 & 65 & 110 & 142 & 95 & 24 & 25 \\
\hline W.K. & 35 & 120 & 142 & 100 & 46 & 40 & 36 \\
\hline A.C. & 19 & 88 & 84 & 52 & 14 & 26 & 11 \\
\hline A.B. & 42 & 112 & 214 & 93 & 22 & 41 & 25 \\
\hline P.B. & 26 & 91 & 148 & 116 & 68 & 29 & 30 \\
\hline Means \pm S.D. & $\begin{array}{r}+9 \\
26-6\end{array}$ & $\begin{array}{r}+76 \\
98-43\end{array}$ & $\begin{array}{r}+83 \\
141-52\end{array}$ & $\begin{array}{r}+61 \\
98-38\end{array}$ & $\begin{array}{r}+45 \\
48-23\end{array}$ & $\begin{array}{r}+16 \\
32-11\end{array}$ & $\begin{array}{r}+19 \\
25-11\end{array}$ \\
\hline \multicolumn{8}{|l|}{ Controls } \\
\hline I.A. & 25 & 21 & 64 & 67 & 50 & 23 & 23 \\
\hline A.M. & 22 & 76 & 78 & 33 & 29 & 24 & 29 \\
\hline T.G. & 4 & 38 & 58 & 73 & 35 & 19 & - \\
\hline A.C. & 45 & - & 110 & 80 & 35 & 35 & 15 \\
\hline R.H. & 35 & 89 & 78 & 93 & 65 & 37 & - \\
\hline K.B. & 33 & 82 & 82 & 71 & 28 & 23 & - \\
\hline G.M. & 4 & 45 & 55 & 20 & 5 & 5 & - \\
\hline W.P. & 83 & - & 130 & 170 & 77 & - & 55 \\
\hline K.C. & 31 & 90 & 230 & 41 & 55 & 22 & - \\
\hline I.C. & 25 & 125 & 186 & 73 & 39 & 30 & 24 \\
\hline J.McD. & 11 & - & 84 & 107 & 26 & 12 & - \\
\hline A.W. & 6 & 24 & 46 & 40 & 34 & 16 & - \\
\hline U.D. & 19 & 51 & 65 & 68 & 70 & 57 & 61 \\
\hline S.A. & 22 & 140 & 242 & 84 & 107 & 64 & - \\
\hline & +28 & +51 & +66 & +45 & +37 & +23 & +12 \\
\hline Means \pm S.D. & $19-11$ & $59-27$ & $93-38$ & $65-27$ & $35-19$ & $23-11$ & $31-9$ \\
\hline
\end{tabular}

One notable feature was that in both patients and controls the shape of the plasma insulin curve after oral and after intravenous glucose was similar; e.g., those with a rapid transient rise after oral glucose showed a similar pattern after intravenous glucose, and conversely those with a more prolonged plasma insulin rise showed this after both oral and intravenous glucose.

In the ulcer patients the peak plasma insulin level during the glucose tolerance test was higher (for each individual) than that during the intravenous glucose tolerance test (Fig. 1). The mean peak insulin value was significantly higher after oral than intravenous glucose $\left(148{ }_{-50}^{+76}: 78{ }_{-33}^{+57} ; \mathrm{P}>0.01\right)$.

The control subjects showed a variable pattern. Only one (K.C.) showed a very much higher plasma insulin response to oral than to intravenous glucose; eight showed a slightly higher response and five a lower response. The mean peak insulin value after oral glucose was higher than that after intravenous glucose but this was not statistically significant

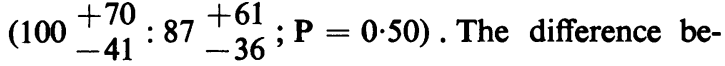
tween the peak insulin levels following oral and intravenous glucose in the duodenal ulcer patients $\left(47^{+79}-38\right)$ was significantly greater than the difference between the corresponding peak insulin levels in control subjects $(3 \stackrel{+99}{+9} ; \mathrm{P}>0.01)$.

AUGMENTED HISTAMINE TEST MEAL The results obtained following maximal histamine stimulation in the duodenal ulcer patients are shown in Table V. No correlation was found between the insulin response to oral glucose and the gastric secretion after histamine.

\section{DISCUSSION}

The reported incidence of hypoglycaemia in association with peptic ulceration varies from $16 \%$ (Evenson, 1942) to $70 \%$ (Berry, 1957). In the 
TABLE III

BLOOD SUGAR RESULTS AFTER $25 \mathrm{~g}$. INTRAVENOUS GLUCOSE IN DUODENAL ULCER SUBJECTS AND CONTROLS Blood Sugar Level (mg./100 ml.)

\begin{tabular}{|c|c|c|c|c|c|c|c|}
\hline & \multicolumn{7}{|c|}{ Blood Sugar Level (mg./100 ml.) } \\
\hline & Fasting & 10 Minutes & 20 Minutes & 30 Minutes & 40 Minutes & 50 Minutes & 60 Minutes \\
\hline $\begin{array}{l}\text { Duodenal } \\
\text { ulcer }\end{array}$ & $89 \pm 19$ & $236 \pm 30$ & $180 \pm 36$ & $149 \pm 40$ & $128 \pm 48$ & $118 \pm 37$ & $100 \pm 41$ \\
\hline $\begin{array}{l}\text { Controls } \\
\text { Means } \pm \text { S.D. }\end{array}$ & $86 \pm 17$ & $237 \pm 29$ & $175 \pm 41$ & $141 \pm 38$ & $118 \pm 30$ & $98 \pm 25$ & $88 \pm 22$ \\
\hline
\end{tabular}

TABLE IV

PLASMA INSULIN RESPONSE TO 25 g. INTRAVENONS GLUCOSE IN DUODENAL ULCER SUBJECTS AND CONTROLS

Plasma Insulin (micro-units/ml.)

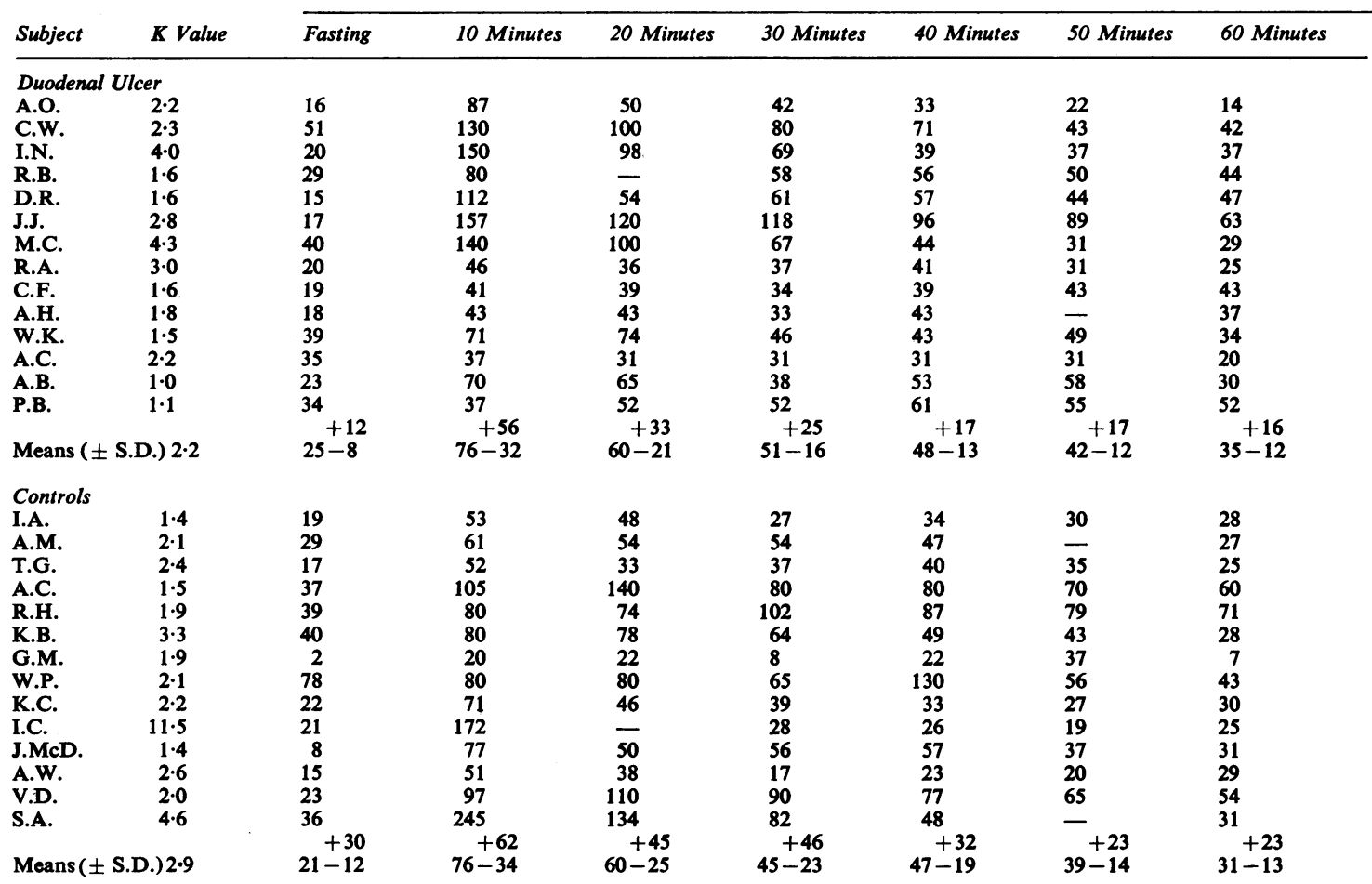

present series four patients $(28.6 \%)$ had blood sugar levels below $60 \mathrm{mg}$. per $100 \mathrm{ml}$. at some time after oral glucose, an incidence which is similar to that of Muir (1949). However, none of our patients experienced either hypoglycaemic symptoms or ulcer pain in association with these levels and two of the controls had similar low levels of glucose. The mean minimal blood sugar value, irrespective of timing, was similar in ulcer patients and controls. More cases of hypoglycaemia might have emerged had the glucose tolerance test been prolonged beyond two and a half hours and true glucose levels been estimated rather than total reducing substances.
We did not confirm the high incidence of the 'lag storage' curve reported by Platt, Dotti, and Beekman (1949) nor did the intravenous glucose tolerance tests in the present series show the significantly delayed fall in blood sugar values which they reported. However, their patients were considerably older, which may have been a contributing factor (Crockford, Harbeck, and Williams, 1966), although they discounted it. Despite the finding of normal glucose tolerance in the majority of duodenal ulcer patients there was a significant increase in the plasma insulin response to oral glucose, though not to intravenous glucose, as compared with control subjects. 


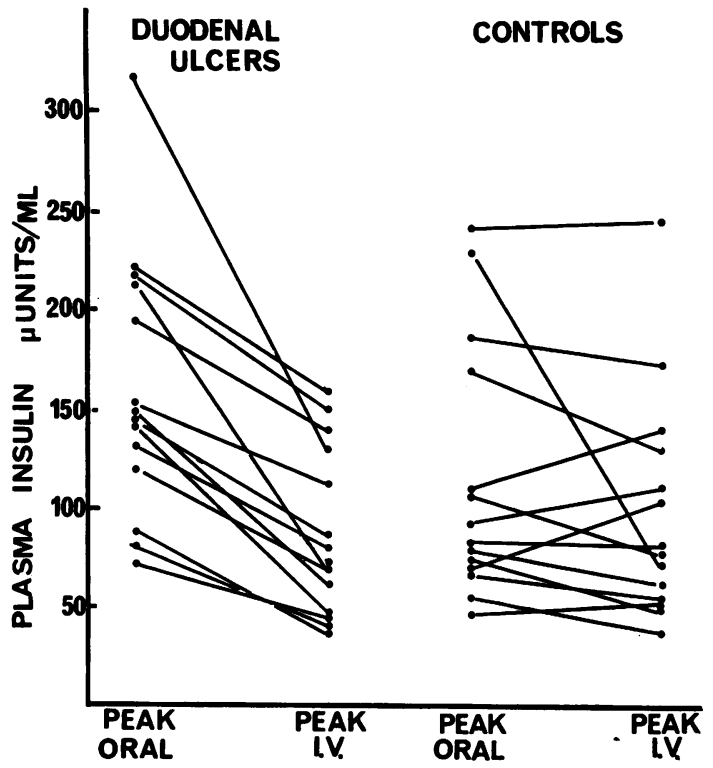

FIG. 1. The peak insulin response to oral and intravenous glucose is compared in duodenal ulcer subjects and controls.

TABLE V

RESULTS OF AUGMENTED HISTAMINE TESTS IN DUODENAL ULCER SUBJECTS

\begin{tabular}{|c|c|c|c|c|c|}
\hline \multirow[b]{2}{*}{ Subject } & & \multirow{2}{*}{\multicolumn{2}{|c|}{$\begin{array}{l}\text { Value of Gastric Juice pH } \\
\qquad(\mathrm{ml} .)\end{array}$}} & \multicolumn{2}{|c|}{$H C L(m E q . \mid l)}$. \\
\hline & & & & Free & Total \\
\hline \multirow[t]{2}{*}{ A.O. } & $\begin{array}{l}\mathbf{A} \\
\mathbf{B}\end{array}$ & $\begin{array}{l}21 \\
96\end{array}$ & $<1$ & 40 & 50 \\
\hline & & 96 & $<1$ & 116 & 122 \\
\hline C.W. & $\begin{array}{l}\mathbf{A} \\
\mathbf{B}\end{array}$ & $\begin{array}{r}81 \\
152\end{array}$ & $<1^{1-2}$ & $\begin{array}{l}20 \\
84\end{array}$ & $\begin{array}{l}26 \\
96\end{array}$ \\
\hline \multirow[t]{2}{*}{ I.N. } & $\mathbf{A}$ & 12 & $8 \cdot 3$ & - & 2 \\
\hline & B & 190 & $<1$ & 70 & 76 \\
\hline \multirow[t]{2}{*}{ R.B. } & $\mathbf{A}$ & 13 & $1-2$ & 22 & 26 \\
\hline & B & 26 & $<1$ & 70 & 76 \\
\hline \multirow[t]{2}{*}{ D.R. } & $\mathbf{A}$ & 19 & 2 & 26 & 32 \\
\hline & B & 70 & 1 & 232 & 259 \\
\hline \multirow[t]{2}{*}{ J.J. } & $\mathbf{A}$ & 20 & $<1$ & 28 & 38 \\
\hline & $\mathbf{B}^{1}$ & 5 & 2 & - & 10 \\
\hline \multirow{3}{*}{$\begin{array}{l}\text { M.C. } \\
\text { R.A. }\end{array}$} & & & not done & & \\
\hline & $\mathbf{A}$ & 81 & $1-2$ & 14 & 22 \\
\hline & B & 152 & $<1$ & 78 & 86 \\
\hline \multirow[t]{2}{*}{ C.F. } & $\mathbf{A}$ & 49 & $1-2$ & 22 & 36 \\
\hline & B & 252 & $<1$ & 88 & 96 \\
\hline \multirow[t]{2}{*}{ A.H. } & $\mathbf{A}$ & 46 & 1 & 34 & 42 \\
\hline & B & 262 & 1 & 312 & 400 \\
\hline \multirow[t]{2}{*}{ W.K. } & $\mathbf{A}$ & 12 & - & - & - \\
\hline & B & 55 & 1 & 298 & 322 \\
\hline \multirow[t]{2}{*}{ A.C. } & $\mathbf{A}$ & $2 \cdot 4$ & $6 \cdot 4$ & - & - \\
\hline & B & 115 & 1.0 & 80 & 90 \\
\hline \multirow[t]{2}{*}{ A.B. } & $\mathbf{A}$ & 0.4 & $8 \cdot 0$ & - & - \\
\hline & $B^{2}$ & 6.0 & 4.0 & 20 & 42 \\
\hline \multirow[t]{2}{*}{ P.B. } & $\mathbf{A}$ & 10 & 1 & 38 & 50 \\
\hline & B & 15 & 1 & 58 & 70 \\
\hline
\end{tabular}

${ }^{1}$ Results suggest that the intragastric tube was not correctly positioned.
Can this increase in plasma insulin response to oral glucose be related simply to more rapid absorption of glucose in patients with duodenal ulcers? The higher 15-minute blood sugar value in the ulcer patients certainly suggests more rapid glucose absorption. However, only three of the ulcer patients had their peak blood sugar value at 15 minutes and two of the controls also had their peak blood sugar at 15 minutes. The low incidence of the 'lag' curve is also against very rapid glucose absorption. We have shown (Buchanan and McKiddie, 1967b) that in normal subjects the shape of plasma insulin curve closely resembles the blood sugar curve. Therefore, although higher early blood sugars might produce higher plasma insulin levels initially, this would not explain the higher insulin levels as late as $\mathbf{6 0}$ minutes after oral glucose.

Another interesting feature is that, in spite of the higher insulin levels, the blood sugar level did not fall lower than in the controls, and the patients who developed hypoglycaemia were not those with the highest insulin levels. This would perhaps suggest a degree of insulin resistance but this is not borne out by the results of the intravenous glucose tolerance tests where the results were similar to the controls. Muir (1949) suggested that duodenal ulcer patients showed an exaggerated sensitivity to insulin as judged by the insulin test meal. However, the plasma insulin levels attained during an insulin test meal are very much higher than those under discussion.

Can these differences in carbohydrate metabolism be related to peptic ulceration? McIntyre et al. (1964) have shown that oral glucose produces a greater insulin response than a comparable stimulus of intravenous glucose. The tests used in the present series were not directly comparable but it did appear that in duodenal ulcer patients oral glucose produced a greater insulin rise relative to intravenous glucose than in control subjects. It is possible that the altered gastrointestinal functions associated with peptic ulceration may produce the increase in insulin levels after oral glucose through the action of either glucagon or secretin. Glucagon stimulates insulin production (Samols, Tyler, Marri, and Marks, 1965b; Turner and McIntyre, 1965) and has been shown to be secreted after oral but not after intravenous glucose (Samols, Marri, and Marks, 1965a). Furthermore glucagon has been isolated from gastrointestinal tissues (Makman and Sutherland, 1964). Duodenal ulcer patients may either secrete an increased amount of glucagon after oral glucose or have a greater sensitivity to its insulinreleasing action. Glucagon is also a hyperglycaemic factor (Unger and Eisentraut, 1964) which might explain the apparent insulin resistance. 
Dupré, Rojas, White, Unger, and Beck (1966) suggest that secretin may be released after oral glucose and that this is the factor stimulating the greater insulin secretion after oral glucose. Secretin has been shown to increase the disappearance rate of intravenous glucose (Dupré, 1964). The increased gastric acidity associated with duodenal ulceration may stimulate the production of an excessive amount of secretin with a secondary rise in insulin secretion. However, Boyns, Jarrett, and Keen (1966) were unable to show an increase in insulin production after acid had been instilled into the duodenum in normal subjects, and in the present series there was no apparent correlation between maximal gastric acid secretion and the insulin response to oral glucose.

More intriguing is the possibility that these changes in carbohydrate metabolism may predispose towards peptic ulceration. Insulin is commonly thought to exert its effect on gastric secretion via hypoglycaemia (Hollander, 1946) but Aylett (1962a, 1965) has shown that both small doses of insulin and tolbutamide cause an increase in gastric secretion despite only a mild fall in the blood sugar level. It is conceivable, therefore, that the increased insulin levels after oral glucose shown in the duodenal ulcer patients may be a factor in the production of the increased acid secretion associated with peptic ulceration.

If excess glucagon were being released this also might alter gastric function. However, although there are isolated reports of glucagon stimulating gastric acid secretion (Jow, Webster, and Skoryna, 1960), the majority of workers support the view that glucagon inhibits gastric secretion (Bintliff, Condon, and Harkins, 1963; Earle, Cahill, and Hoar, 1957; Robinson, Harris, Hlad, and Eiseman, 1957; Cohen, Mazure, Dreiling, and Janowitz, 1959; Dreiling and Janowitz, 1959) and decreases gastric motility (Stunkard, Van Itallie, and Reis, 1955; Robinson et al., 1957; Aylett, 1962b). These effects would therefore appear to have a protective rather a damaging effect on the gastric mucosa.

\section{SUMMARY}

Abnormalities of carbohydrate metabolism have been reported to occur in association with peptic ulceration. Oral and intravenous glucose tolerance tests were performed in 14 patients with duodenal ulceration and in 14 control subjects. Plasma insulin levels were measured by immunoassay. Blood sugar levels following oral glucose were similar in the two groups but plasma insulin levels were significantly higher in the ulcer patients. The intravenous glucose tolerance tests produced almost identical blood sugar and plasma insulin levels in both groups. The possible significance of these findings is discussed.

We are grateful to Dr A. H. Imrie for help and encouragement in the preparation of this paper. We thank members of the Biochemistry Department for the blood sugar estimations and gastric analysis.

\section{REFERENCES}

Arapakis, G., Bock, O. A. A., Williams, D. L., and Witts, L. J. (1963). Diabetes mellitus and pernicious anaemia. Brit. med. J., 1, 159-161.

Aylett, P. (1962a). Gastric emptying and change of blood glucose level, as affected by glucagon and insulin. Clin. Sci., 22, 171-178.

- (1962b). The effects of glucagon and glucagon-free insulin upon gastric secretion in peptic ulcer patients. Ibid., 22, 179-184.

(1965). Effects of tolbutamide upon gastric secretion and emptying. Brit. med. J., 1, 1464-1466.

Berry, M. (1957). Studies of the unknown factors in duodenal ulcer. Hypoglycemia as a possible etiological factor. Amer. $J$. Gastroent., 27, 31-44.

Bintliff, S. J., Condon, R. E., and Harkins, H. N. (1963). Effect of glucagon on gastric secretion in the rat with pyloric occlusion. J. surg. Res., 3, 318-320.

Boyns, D. R., Jarrett, R. J., and Keen, H. (1966). Intestinal hormones and plasma-insulin. Lancet, 1, 409-410.

Buchanan, K. D., and McKiddie, M. T.(1967a). Experience with the immunoprecipitation technique of insulin assay with reference to sensitivity, precision and specificity. Clin chim. Acta, 15, 315-320.

- , $(1967 b)$. The normal insulin response to glucose: Comparison between standard oral and intravenous glucose tolerance tests. To be published.

Caridis, D. T., Blair, D. W., Kilpatrick, S. J., and Carr, A. J., (1966). The effect of alloxan on gastric secretion. Scot. med. J., 11, 247-249.

Cohen, N., Mazure, P., Dreiling, D. A., and Janowitz, H. D. (1959). Effect of glucagon on histamine-stimulated gastric secretion in man. (Abstr.) Fed. Proc., 18, 28.

Crockford, P. M., Harbeck, R. J., and Williams, R. H. (1966). Influence of age on intravenous glucose tolerance and serum immunoreactive nsulin. Lancet, 1, 465-467.

Dotevall, G. (1959). Incidence of peptic ulcer in diabetes mellitus. Acta med. scand., 164, 463-477.

- (1961). Gastric secretion of acid in diabetes mellitus during basal conditions and after maximal histamine stimulation. Ibid., 170, 59-69.

Dreiling, D. A., and Janowitz, H. D. (1959). The effect of glucagon on gastric secretion in man. Gastroenterology, 36, 580-581.

Dupré, J. (1964). An intestinal hormone affecting glucose disposal in man. Lancet, 2, 672-673.

-, Rojas, L., White, J. J. Unger, R. H., and Beck, J. C. (1966). Effects of secretin on insulin and glucagon in portal and peripheral blood in man. Ibid. 2, 26-27.

Earle, A. S., Cahill, G. F., Jr., and Hoar, C. S. Jr. (1957). Studies on the relationship of glucagon (HGF) to blood pepsinogen concentrations. Ann. Surg., 146, 124-130.

Etienne-Martin, P., Klepping ,C., Petit, A., Guerrin, J., and Michiels, R. (1960). L'hypoglycémie de l'ulcère gastro-duodenal. J. Mèd. Lyon, 41, 609-634.

Evanson, O. K. (1942). Alimentary hypoglycemia after stomach operations and influence of gastric emptying on glucose tolerance curve. Acta med. scand., suppl. 126.

Hales, C. N., and Randle, P. J. (1963). Immunoassay of insulin with insulin-antibody precipitate. Biochem. J., 88, 137-146.

Hollander, F., (1946). The insulin test for the presence of intact nerve fibers after vagal operations for peptic ulcer. Gastroenterology, 7, 607-614.

Jow, E., Webster, D. R., and Skoryna, S. C. (1960). Effects of glucagon and insulin on gastric secretion in rats. Ibid., 38, 732-739.

Kay, A. W. (1953). Effect of large doses of histamine on gastric secretion of $\mathrm{HCl}$ : an augmented histamine test. Brit. med. J., 2, 77-80.

Lundbaek, K. (1962). Intravenous glucose tolerance as a tool in definition and diagnosis of diabetes mellitus. Ibid., 1, 1507-1513. 
McIntyre, N., Holdsworth, C. D., and Turner, D. S. (1964). New interpretation of oral glucose tolerance. Lancet, 2 20-21.

Makman, M. H., and Sutherland, E. W., Jr. (1964). Use of liver adenyl cyclase for assay of glucagon in human gastro-intestinal tract and pancreas. Endocrinology, 75, 127-134.

Moore, J. M., and Neilson, J. McE. (1963). Antibodies to gastric mucosa and thyroid in diabetes mellitus. Lancet, 2, 645-647.

Muir, A. (1949). Carbohydrate metabolism and gastric secretory activity. Quart. J. Med., 18, 235-261.

Platt, W. D., Jr., Dotti, L. B., and Beekman, R. S. (1949). Glucose tolerance in patients with a peptic ulcer. Gastroentreology, 13, 20-30.

Robinson, R. M., Harris, K., Hlad, C. J., and Eiseman, B. (1957).
Effect of glucagon on gastric secretion. Proc. Soc. exp. Biol. (N.Y.), 96, 518-520.

Samols, E., Marri, G., and Marks, V. (1965a). Promotion of insulin secretion by glucagon. Lancet, 2, 415-416.

—, Tyler, J., Marri, G., and Marks, V. (1965b). Stimulation of glucagon secretion by oral glucose. Ibid. 2, 1257-1259.

Stunkard, A. J., Van Itallie, T. B., and Reis, B. B. (1955). The mechanism of satiety: effect of glucagon on gastric hunger contractions in man. Proc. Soc. exp. Biol. (N.Y.), 89, 258-261.

Turner, D. S., and McIntyre, N. (1966). Stimulation by glucagon of insulin release from rabbit pancreas in vitro. Lancet, 1, 351-352.

Unger, R. H., and Eisentraut, A. M. (1964). Studies of the physiologic role of glucagon. Diabetes, 13, 563-568. 